\title{
Identification and Genetic Diversity Analysis of Rickettsia in Dermacentor Nuttalli Within Inner Mongolia, China
}

\section{Zheng Gui}

Ningbo Huamei Hospital University of Chinese Academy of Sciences

Hao Cai

Ningbo Huamei Hospital University of Chinese Academy of Sciences

Dong-Dong Qi

Mental Health Center

Shun Zhang

Ningbo Huamei Hospital University of Chinese Academy of Sciences

\section{Shao-Yin Fu}

Inner Mongolia Academy of Agricultural and Animal Husbandry Sciences

Rui Mao ( $\square$ maorui@ucas.ac.cn)

Ningbo Huamei Hospital University of Chinese Academy of Sciences

Jing-Feng Yu

Inner Mongolia Medical University

\section{Xiao-Yan Si}

Inner Mongolia Center for Disease Control and Prevention

\section{Ting Cai}

Ningbo Huamei Hospital University of Chinese Academy of Sciences

\section{Research Article}

Keywords: Rickettsia, gltA, ompA, Rickettsia identification, genetic diversity

Posted Date: November 19th, 2021

DOI: https://doi.org/10.21203/rs.3.rs-1082354/v1

License: (c) (i) This work is licensed under a Creative Commons Attribution 4.0 International License. Read Full License 


\section{Abstract \\ Background}

The pathogen genus Rickettsia contains the linages spotted fever group, typhus group, transitional group, and the ancestral group, of which the spotted fever group Rickettsia (SFGR) is transmitted by ticks. Dermacentor nuttalli is considered the main vector carrying SFGR. Studying the genetic diversity and population structure of Rickettsia is essential for developing effective control strategies and predicting evolutionary trends of the pathogens.

\section{Methods}

We collected 408 Dermacentor nuttalli in the Inner Mongolia Autonomous region in 2019, detected Rickettsia infection, and characterized the haplotypes. The extracted Rickettsia DNA of the gltA and ompA genes were amplified and sequenced.

\section{Result}

In this study, 10 haplotypes of the gltA gene and 22 haplotypes of the ompA gene were obtained. In the two resulting phylogenetic trees, the haplotypes G1-G7 and G9 of the gltA gene clustered with Rickettsia raoultii, while G8 and G10 clustered with Rickettsia sibirica. Haplotypes 01-015, 018 and 020-022 of the ompA gene clustered with Rickettsia raoultii, while 016 and 019 clustered with Rickettsia sibirica. The average haplotype diversity was 0.3 for gltA and 0.7 for ompA, while the average nucleotide diversity was

greater than 0.05 . Neutrality tests were insignificant for Tajima's D results and Fu's Fs results. The fixation index values $\left(F_{S T}\right)$ showed that the degree of genetic differentiation between most sampled populations was small $\left(F_{S T}<0.05\right)$, while others were medium $\left(F_{S T}>0.05\right)$ and large $\left(F_{S T}>0.15\right)$. Analysis of molecular variance (AMOVA) revealed that the variation within populations was greater than that between populations. The mismatch analysis of Rickettsia showed double peaks.

\section{Conclusion}

We found two genotypes of Rickettsia: Rickettsia raoultii and Rickettsia sibirica. The high genetic diversity of Rickettsia allows for easy adaption to different environments; furthermore, genetic differentiation between populations is small and Rickettsia populations do not show a pedigree geographical structure. The high rates of retention and infestation of Rickettsia in Dermacentor nuttalli together with the animal husbandry exchange in China gradually lead to the genetic characteristics of Rickettsia harmonizing across various regions. Overall, the significant genetic diversity and geographic structure of Rickettsia in Dermacentor nuttalli are critical for SFGR control. 


\section{Background}

Rickettsia is an important zoonotic pathogen. It brings great harm to the health of humans and animals $[1,2]$. According to the phylogeny of Rickettsia, its species belong to four groups: spotted fever group (SFG), typhus group (TG), transitional group (TRG), and ancestral group (AG). SFG is transmitted by ticks $[3,4]$, while TG is transmitted by lice and fleas [5]. The vast territory and diverse habitats of Inner Mongolia greatly benefit the survival of ticks. Dermacentor nuttalli, is the dominant tick species, and is considered to be the main vector carrying SFGR in Inner Mongolia [6-8]. SFGR infections occur around the world and may cause serious diseases in humans. In China Rickettsia heilongjiang Fournier et al., 2003, Rickettsia raoultii Mediannikov et al. 2008, Rickettsia slovaca Sekeyová et al. 1998, Rickettsia sibirica Zdrodovskii, 1948, Rickettsia mongolotimonae Roux et al. 1997, Rickettsia monacensis Simser et al. 2019, and Candidatus Rickettsia hebeiii Zou et al. 2011 and Candidatus Rickettsia jingxinensis Liu et al. 2016 have been detected in ticks. In recent years, an increasing number of potentially novel SFGR have been detected in ticks, emphasizing that SFGR pose a threat to public health in China [9-12].

Molecular biological techniques allow for the identification of Rickettsia species. Although 16S rRNA can accurately identify a pathogen as belonging to Rickettsia, it is hard to distinguish the species due to the fact that in almost all prokaryotes this is a highly conserved region. The gltA and ompA genes are used for species identification in Rickettsia [13-16]. The gltA gene encodes a citrate lyase, the sequence of which allows for a highly reliable identification of the evolutionary distances among Rickettsia. The ompA gene is an outer membrane protein gene and is considered as the 'gold-standard' for species identification in Rickettsia, owing to the highly specific 5'end [17].

Previous studies demonstrated that the genetic diversity of Dermacentor nuttalli is rich and allows for its existence in different geographical environments [18]. Therefore, in our investigation we increased the number of tick species, exploring the Rickettsia infection and genotype distribution, furthering to analyze the genetic diversity of Rickettsia. Studying the genetic diversity of Rickettsia is essential for developing effective control strategies and predicting pathogen evolutionary trends.

\section{Methods}

\section{Sample collection}

In this study, a total of 408 ticks were collected from sheep at four sampling spots in Inner Mongolia, China, namely Chengchuan Town, early Banner of Etoke Banner Ordos; Siziwang Banner; Hohhot; the Bayan WenduSumu area Arukorqin Banner Chifeng and Xinbarhu right Banner, Hulun Buir. The locations of the sampling areas are shown in Supplementary Table1.

\section{DNA extraction, amplification and sequencing}

Ticks were identified as Dermacentor nuttalli, all Dermacentor nuttalli samples were individually extracted using TIANGEN Tissue and Blood Kit (TIANGEN, Beijing, China) [19]. For identification of Rickettsia 
infections, Rickettsia gltA and ompA genes were amplified by PCR following the protocols described by Bermúdez et al [20].

Specific primers targeting gltA and ompA genes of Rickettsia from Dermacentor nuttalli were synthesized by Shanghai Sangon. DNA was amplified using a system of $40 \mu \mathrm{L}$, each including Taq PCR Master Mix (Sangon), $2 \mu \mathrm{L}$ of DNA from each sample, $1 \mu \mathrm{L}$ of each reverse and forward primers, filled up with sterile water. The PCR primers, amplification sizes (bp), and annealing temperatures are presented in Table 2. Sterile double distilled water was used as the negative control in each PCR reaction. After checking the PCR products with a $1.5 \%$ agarose gel electrophoresis stained with GoldeView, PCR products were directly sent for sequencing if the result presented a single band. Otherwise, the PCR product was purified using the Gel DNA Recovery Kit (TIANGEN, Beijing, China) and cloned using the p-GMT Easy vector system.

Table 1

Sample information of Dermacentor nuttalli populations

\begin{tabular}{|llllll|}
\hline Location & Collection time & Area code & Longitude & Latitude & Samples \\
\hline ChiFeng & 2019.4 & CF & $121^{\circ} 64^{\prime}$ & $43^{\circ} 46^{\prime}$ & 219 \\
\hline Siziwang Banner & 2019.5 & SZWQ & $111^{\circ} 63^{\prime}$ & $40^{\circ} 81^{\prime}$ & 30 \\
\hline Hulun Buir & 2019.8 & HLBE & $116^{\circ} 82^{\prime}$ & $48^{\circ} 67^{\prime}$ & 74 \\
\hline Ordos & 2019.7 & EEDS & $108^{\circ} 32^{\prime}$ & $37^{\circ} 70^{\prime}$ & 85 \\
\hline
\end{tabular}

Table 2

Primers of PCR and amplification conditions

\begin{tabular}{|llll|}
\hline $\begin{array}{l}\text { Gene } \\
\text { target }\end{array}$ & Primer sequence(5' ${ }^{\prime}$ ') & Amplification size(bp) & Annealing temperature $\left({ }^{\circ} \mathbf{C}\right)$ \\
\hline gltAF & CGATTGCTTTACTTACGACCC & 1090 & 53 \\
gltAR & GAGCATTTCTTTCCATTGTGCC & \\
\hline ompAF & ACTAGGTGCGAATATAGACCC & 712 & 56 \\
\hline ompAR & CGTACCTTTTGCGTTAACACT & \\
\hline Table3 Rickettsia infection in Dermacentor nuttalli & \\
\hline
\end{tabular}

\section{Data analysis}

Sequences were edited in Seqman 7.1 and identified by comparative analysis with sequences deposited in GenBank, using the BLAST search engine. Multiple sequence alignment and sequence similarity calculations were done using DNAMAN 7.0. Phylogenetic trees were reconstructed with the neighborjoining algorithm using MEGA7.0 with 1000 Bootstrap replicates to assess tree stability [21-23]. Sequences were analyzed in DNAsp 5.10 and Arequin 3.5 for calculating polymorphic sites, nucleotide differences, the number of haplotypes, both haplotype and nucleotide diversity, the distribution pattern of DNA variation haplotype, and genetic variation parameters [24, 25]. The extent of molecular genetic 
differentiation among Rickettsia populations analyzed from Inner Mongolia was estimated by analysis of molecular variance (AMOVA) and $\mathrm{F}_{\mathrm{ST}}$ values [26]. To determine whether genetic differentiation and population structures of Rickettsia varied between the four sampling localities in Inner Mongolia. Neutral tests were analyzed using Tajima's D and Fu's Fs tests using Arequin 3.5 and DNAsp 5.10. Popart 1.7 was used to evaluate the relationships between haplotypes by constructing TCS haplotype network maps.

\section{Results}

\section{Rickettsia infection}

We collected and tested a total of 408 D. nuttalli in 2019 from four sites in Inner Mongolia: Chifeng $(n=219)$, Orods $(n=85)$, Siziwang Banner $(n=30)$, and Hulunbeier $(n=74)$ (Table3). Positive amplification products of the gltA and ompA genes were regarded as the infection rate of Rickettsia in Dermacentor nuttalli [27]. Across the four regions, the average infection rate of Rickettsia was $50.74 \%$, with is the highest value found in the Hulunbeier region (85.14\%).

\section{Rickettsia identification}

PCR amplicons from positive samples were cloned and sequenced. We detected 10 haplotypes of gltA sequences (Genbank Accession Numbers OK638141-OK638150) and 22 haplotypes of ompA sequences (Genbank Accession Numbers OL304270-OL304271, OL348251-OL348270). The sequences had the highest similarities with Rickettsia raoultii and Rickettsia sibirica, as registered in Genbank, with $98 \%$ and 99\% identity respectively. In the gltA phylogenetic trees, haplotypes G1-G7 and G9 were clustered with Rickettsia raoultii, while G8 and G10 were clustered with Rickettsia sibirica. Furthermore, Rickettsia in Inner Mongolia is closely related to Candidatus Rickettsia uralica Igolkina et al. 2015 with 98\% identity and distantly related to Rickettsia asembonensis Maina et al. 2016. In the ompA phylogenetic trees, Haplotypes 01-015, 018, and 020-022 were clustered with Rickettsia raoultii, while 016 and 019 were clustered with Rickettsia sibirica. Rickettsia in Inner Mongolia is closely related to Candidatus Rickettsia uralica with $98 \%$ identity and distantly related to Rickettsia montana (ex Lackman et al. 1965) Weiss and Moulder 1984. The phylogenetic trees for both genes showed that the haplotypes of Rickettsia clustered into one branch with the ingroup, which had two genotypes, Rickettsia raoultii and Rickettsia sibirica, in this study (Fig.1, 2).

\section{Rickettsia genetic diversity by gltA gene}

Of 10 haplotypes recovered, 4 were shared haplotypes (G1, G2, G3, G10). Numerically, the most common haplotype was $\mathrm{G} 1$, with 167 sequences $(80.68 \%$ of all sequences) (Table4). G1 was located in the center of the haplotype network diagram and was found in four geographic populations, indicating that it was the dominant haplotype among groups (Fig.3a). The average haplotype diversity was 0.335 and the average nucleotide diversity was 0.04922 . EEDS was the region with the highest haplotype diversity $(h=0.909)$. Neutrality results revealed insignificant values of Tajima's $D$ and Fu's Fs results, confirming that the population had not experienced recent expansion (Table 5). The Wright's $F$ index was calculated 
to measure the levels of genetic differentiation among the four geographical populations. Comparing pairwise $F_{S T}$ indices exhibited that the $F_{S T}$ value between HLBE and SZWQ was greater than 0.25 , indicating that there was high genetic differentiation among populations. The $\mathrm{F}_{\mathrm{ST}}$ values among the other regions were less than 0.05 , indicating that the genetic differentiation amongst these populations was very small (Table 6). The AMOVA results showed that the population variation of Rickettsia mainly arose from within the population, and the genetic differentiation between populations was very small (Table 7). The mismatch analysis chart exhibited double peaks, indicating that the four geographic populations did not experience rapid population expansion (Fig. 4a).

\section{Rickettsia genetic diversity by ompA gene}

Of the 22 haplotypes that were found, 4 were shared haplotypes $(01,02,03,016)$. Numerically, the most common haplotypes were 01,02 , and 03 , with 170 sequences ( $82.13 \%$ of all sequences) (Table 8 ). 02 was located in the center of the network map and was found in four geographic populations, indicating that it was the dominant haplotype among groups (Fig.3b). The total average haplotype diversity was 0.735 and the total nucleotide diversity was 0.0738 . SZWQ was the locality with the highest haplotype diversity $(\mathrm{h}=1)$ (Table 10). Neutrality results were the same as those for gltA (Table 9). Comparing pairwise $F_{S T}$ indices exhibited that the $F_{S T}$ value between $C F$ and HLBE was greater than 0.25 , indicating that there was a high genetic differentiation among populations. The $F_{S T}$ values between HLBE『SZWQ and EEDS were all greater than 0.05 , indicating that there was a moderate genetic differentiation among populations. The $F_{S T}$ values among the other regions were less than 0.05 , indicating that the genetic differentiation amongst these populations was very small (Table 10). The results of the AMOVA and mismatch analyses were consistent with the gltA results (Table11, Fig.4b).

\section{Discussion}

In addition to evaluating the emergence of new genotypes and studying the population structure, investigations of the genetic diversity of Rickettsia are critical for planning effective control measures. This study analyzed the genetic diversity of the gltA and ompA genes of Rickettsia from four localities of Inner Mongolia. Two genotypes of Rickettsia have been identified: Rickettsia raoultii and Rickettsia sibirica, both belong to SFGR. However, in recent years, human infection with Rickettsia raoultii in many countries led to tick-borne lymphadenitis [28-31]. Public health workers and physicians should pay attention to the high risk of humans being infected by Rickettsia raoultii, to strengthen appropriate detection and treatment measures in endemic regions.

Our results illustrated that the gltA and ompA genes have shared haplotypes in four regions, which are dominant haplotypes characterized as primitive and stable. Shared haplotypes indicate that the degree of gene communication is high in Rickettsia populations. We found $\mathrm{Hd}>0.5, \mathrm{Pi}>0.005$ as the highest genetic diversity [32]. The lowest genetic diversity was found in HLBE in the gltA gene, while the diversity of the ompA was markedly higher in HLBE. The genetic diversity of species is affected by many factors, including geographical distribution, population size, and other natural factors. Different gene markers are 
under different selective pressures during the evolution of species, leading to inconsistent genetic diversities [33,34]. Overall, the high genetic diversity of Rickettsia is in accordance with different environments. Among four geographic populations, the degree of genetic differentiation was high only between HLBE and SZWQ in the gltA gene. The degree of genetic differentiation was large between HLBE and the other three regions. We concluded that the genetic differentiation in some regions is not within the same range due to the different evolutionary rates of the two genes. The neutrality test and the mismatch analysis maps for the two genes exhibited genetic differentiation with no population expansion. The haplotypes of Rickettsia did not branch clearly according to the clustering of geographic regions, documenting that the Rickettsia populations did not form a pedigree geographical structure. Since Rickettsia can be transmitted either vertically or horizontally, the high retention and infestation rates of Rickettsia in Dermacentor nuttalli, together with the animal husbandry exchange in China gradually lead to the harmonization of genetic characteristics of Rickettsia across various regions. Overall, the significant genetic diversity and geographic structure exhibited among Rickettsia in Dermacentor nuttalli has critical implications for SFGR control.

\section{Conclusion}

The gltA and ompA genes were used to study the genetic diversity of Rickettsia from four geographic localities in Inner Mongolia. This study provides a reference for avoiding the risk of introducing new genotypes and complex genetic structures of Rickettsia populations, at the same time, it fills a gap in the knowledge of the genetic diversity of Rickettsia in Inner Mongolia.

\section{Additional files}

\section{Abbreviations}

PCR

Polymerase chain reaction

D. nuttalli

Dermacentor nuttalli

R. raoultii

Rickettsia raoultii

R. sibirica

Rickettsia sibirica

AMOVA

Analysis of molecular variance

BLAST

Basic Local Alignment Sequence Tool.

\section{Declarations}




\section{Declarations}

Ethics approval and consent to participate

\section{Declarations}

Consent for publication

Not applicable.

\section{Declarations}

Competing interests

The authors declare that they have no competing interests.

\section{Declarations}

\section{Abbreviation}

n, number of samples; $\mathrm{Ht}$, number of haplotypes; $\mathrm{S}$, number of polymorphic sites; $\mathrm{Hd}$, haplotype diversity; $\mathrm{Pi}$, nucleotide diversity. ${ }^{*} p<0.05 ; * \star p<0.01 ; * \star \star * 0<0.001$

\section{Declarations}

\section{Abbreviation}

$\mathrm{n}$, number of samples; $\mathrm{Ht}$, number of haplotypes; $\mathrm{S}$, number of polymorphic sites; $\mathrm{Hd}$, haplotype diversity;

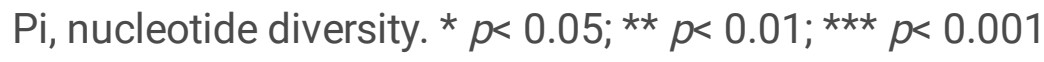

\section{Funding}

This work received financial support from Medical Scientific Research Foundation of Zhejiang Province, China (Grant No. 2021423808), Research Foundation of Ningbo Institute of Life and Health Industry, University of Chinese Academy of Sciences (Grant No. 2020YJY0214 \& 2021YJY1008), Achievement Transformation Project of Inner Mongolia Medical University (Grant no. YKD2020CGZH001), Zhiyuan Talent Project of Inner Mongolia Medical University (Grant no. ZY0201027). 


\section{Authors' contributions}

ZG, HC and DDQ performed laboratory analysis, analyzed data and wrote the first draft. RM, TC, and JFY revised the manuscript. XYS and DDQ participated in samples collection. SYF directed the experiment and helped to revise the manuscript. All authors read and approved the final manuscript.

\section{Acknowledgements}

We are very grateful to Inner Mongolia Center for Disease Control and Prevention for providing tick samples. We are very grateful to Molecular Biology Research Center of Inner Mongolia Medical University for providing experimental facilities and conditions.

\section{References}

1. Parola P, Raoult D. Ticks and tickborne bacterial diseases in humans: an emerging infectious threat. Clin Infect Dis. 2001;32(6):897-928.

2. Černý J, Buyannemekh B, Needham T, Gankhuyag G, Oyuntsetseg D. Hard ticks and tick-borne pathogens in Mongolia-A review. Ticks Tick Borne Dis. 2019;10(6):101268.

3. Guo WP, Wang YH, Lu Q, Xu G, Luo Y, Ni X, et al. Molecular detection of spotted fever group rickettsiae in hard ticks, northern China. Transbound Emerg Dis. 2019;66(4):1587-1596.

4. Satjanadumrong J, Robinson MT, Hughes T, Blacksell SD. Distribution and Ecological Drivers of Spotted Fever Group Rickettsia in Asia. Ecohealth. 2019;16(4):611-626.

5. Raoult D, Roux V. Rickettsioses as paradigms of new or emerging infectious diseases. Clin Microbiol Rev. 1997;10(4):694-719.

6. Fischer T, Myalkhaa M, Krücken J, Battsetseg G, Batsukh Z, Baumann MPO. Molecular detection of tick-borne pathogens in bovine blood and ticks from Khentii, Mongolia. Transbound Emerg Dis. 2020;67(2):111-118.

7. Song S, Chen C, Yang M, Zhao S, Wang B, Hornok S, et al. Diversity of Rickettsia species in border regions of northwestern China. Parasite Vectors. 2018;11(1): 634.

8. Yin X, Guo S, Ding C, Cao M, Kawabata H, Sato K, et al. Spotted Fever Group Rickettsiae in Inner Mongolia, China, 2015-2016. Emerging Infect Dis. 2018;24(11):2105-2107

9. Wang Q, Guo WB, Pan YS, Jiang BG, Du CH, Que TC, et al. Detection of Novel Spotted Fever Group Rickettsiae (Rickettsiales: Rickettsiaceae) in Ticks (Acari: Ixodidae) in Southwestern China. J Med Entomol. 2021;58(3):1363-1369.

10. Guo WP, Wang YH, Lu Q, Xu G, Luo Y, Ni X, et al. Molecular detection of spotted fever group rickettsiae in hard ticks, northern China. Transbound Emerg Dis. 2019;66(4):1587-1596.

11. Fang LQ, Liu K, Li XL, Liang S, Yang Y, Yao HW, et al. Emerging tick-borne infections in mainland China: an increasing public health threat. Lancet Infect Dis. 2015;15(12):1467-1479. 
12. Liu $H$, Liang $X$, Wang $H$, Sun $X$, Bai $X$, Hu B, et al. Molecular evidence of the spotted fever group Rickettsiae in ticks from Yunnan Province, Southwest China. Exp Appl Acarol. 2020;80(3):339-348.

13. Miranda J, S Mattar. Molecular detection of Rickettsia bellii and Rickettsia sp. strain Colombianensi in ticks from Cordoba, Colombia. Ticks Tick Borne Dis. 2014;5(2):208-212.

14. Qin XR, Han HJ, Han FJ, Zhao FM, Zhang ZT, Xue ZF, et al. Rickettsia japonica and Novel Rickettsia Species in Ticks, China. Emerg Infect Dis. 2019;25(5):992-995.

15. Pillay AD, Mukaratirwa S. Genetic diversity of Rickettsia africae isolates from Amblyomma hebraeum and blood from cattle in the Eastern Cape province of South Africa. Exp Appl Acarol. 2020;82(4):529-541.

16. Song S, Chen C, Yang M, Zhao S, Wang B, Hornok S, et al. Diversity of Rickettsia species in border regions of northwestern China. Parasit Vectors. 2018;11(1):634.

17. Roux V, Rydkina E, Eremeeva M, Raoult D. Citrate Synthase Gene Comparison, a New Tool for Phylogenetic Analysis, and Its Application for the Rickettsiae. INTERNATIONAL JOURNAL OF SYSTEMATIC BACTERIOLOGY. 1997;47(2):252-261.

18. Gui Z, Wu L, Cai H, Mu L, Yu JF, Fu SY, et al. Genetic diversity analysis of Dermacentor nuttalli within Inner Mongolia, China. Parasit Vectors. 2021;14(1):131.

19. Halos L, Jamal T, Vial L, Maillard R, Suau A, Le Menach A, et al. Determination of an efficient and reliable method for DNA extraction from ticks. Vet Res. 2004;35:709-713.

20. Bermúdez S, Martínez-Mandiche J, Domínguez L, Gonzalez C, Chavarria O, Moreno A, et al. Diversity of Rickettsia in ticks collected from wild animals in Panama. Ticks Tick Borne Dis. 2021;12(4):101723.

21. Mendell NL, Reynolds ES, Blanton LS, Hermance ME, Londoño AF, Hart CE, et al. Detection of Rickettsiae, Borreliae, and Ehrlichiae in Ticks Collected from Walker County, Texas, 2017-2018. Insects. 2019;10:315.

22. Li K, Stanojević M, Stamenković G, Ilić B, Paunović M, Lu M, et al. Insight into diversity of bacteria belonging to the order Rickettsiales in 9 arthropods species collected in Serbia. Sci Rep. 2019;9:18680.

23. Kumar S, Stecher G, Tamura K. MEGA7: Molecular Evolutionary Genetics Analysis Version 7.0 for Bigger Datasets. Mol Biol Evol. 2016;33:1870-1874.

24. Librado P, Rozas J. DnaSP v5: a software for comprehensive analysis of DNA polymorphism data. Bioinformatics. 2009;25:1451-1452.

25. Rozas J. DNA sequence polymorphism analysis using DnaSP. Methods Mol Biol. 2009;537:337-350.

26. Meirmans PG, Hedrick PW. Assessing population structure: F(ST) and related measures. Mol Ecol Resour. 2011;11:5-18.

27. Santibáñez S, Portillo A, Santibáñez P, Palomar AM, Oteo JA. Usefulness of rickettsial PCR assays for the molecular diagnosis of human rickettsioses. Enferm Infecc Microbiol Clin. 2013;31(5):283-288. 
28. Li H, Zhang PH, Huang Y, Du J, Cui N, Yang ZD, et al. Isolation and Identification of Rickettsia raoultii in Human Cases: A Surveillance Study in 3 Medical Centers in China. Clin Infect Dis. 2018;66(7):1109-1115.

29. Wen J, Jiao D, Wang JH, Yao DH, Liu ZX, Zhao G, et al. Rickettsia raoultii, the predominant Rickettsia found in Dermacentor silvarum ticks in China-Russia border areas. Exp Appl Acarol. 2014;63(4):579585.

30. Dong Z, Yang Y, Wang Q, Xie S, Zhao S, Tan W, et al. A case with neurological abnormalities caused by Rickettsia raoultii in northwestern China. BMC Infect Dis. 2019;19(1):796.

31. Seo MG, Kwon OD, Kwak D. High Prevalence of Rickettsia raoultii and Associated Pathogens in Canine Ticks, South Korea. Emerg Infect Dis. 2020;26(10):2530-2532.

32. Was G, Bowen B W. Shallow population histories in deep evolutionary lineages of marine fishes: Insights from sardines and anchovies and lessons for conservation. Journal of Heredity. 1998(5):415-426.

33. Feng X, Liu J, Chiang YC, Gong X. Investigating the Genetic Diversity, Population Differentiation and Population Dynamics of Cycas segmentifida (Cycadaceae) Endemic to Southwest China by Multiple Molecular Markers. Front Plant Sci. 2017;8:839.

34. [1] Hamrick J L, Godt M J W, Sherman-Broyles S L. Factors influencing levels of genetic diversity in woody plant species. New Forests. 1992;6(1):95-124.

\section{Tables}

Table 1 Sample information of Dermacentor nuttalli populations

\begin{tabular}{|llllll|}
\hline Location & Collection time & Area code & Longitude & Latitude & Samples \\
\hline ChiFeng & 2019.4 & CF & $121^{\circ} 64^{\prime}$ & $43^{\circ} 46^{\prime}$ & 219 \\
\hline Siziwang Banner & 2019.5 & SZWQ & $111^{\circ} 63^{\prime}$ & $40^{\circ} 81^{\prime}$ & 30 \\
\hline Hulun Buir & 2019.8 & HLBE & $116^{\circ} 82^{\prime}$ & $48^{\circ} 67^{\prime}$ & 74 \\
\hline Ordos & 2019.7 & EEDS & $108^{\circ} 32^{\prime}$ & $37^{\circ} 70^{\prime}$ & 85 \\
\hline
\end{tabular}

Table 2 Primers of PCR and amplification conditions 


\begin{tabular}{|c|c|c|c|}
\hline $\begin{array}{l}\text { Gene } \\
\text { target }\end{array}$ & Primer sequence $₫ 5^{\prime} \sim 3^{\prime} \rrbracket$ & $\begin{array}{l}\text { Amplification size } \\
\bigotimes \mathrm{bp} \rrbracket\end{array}$ & $\begin{array}{l}\text { Annealing temperature } \\
\square^{\circ} \mathrm{C} \rrbracket\end{array}$ \\
\hline \multirow{2}{*}{$\begin{array}{l}\text { gltAF } \\
\text { gltAR }\end{array}$} & CGATTGCTTTACTTACGACCC & 1090 & 53 \\
\hline & GAGCATTTCTTTCCATTGTGCC & & \\
\hline ompAF & ACTAGGTGCGAATATAGACCC & 712 & 56 \\
\hline ompAR & CGTACCTTTTGCGTTAACACT & & \\
\hline
\end{tabular}

Table 3 Rickettsia infection in Dermacentor nuttalli

\begin{tabular}{|llllll|}
\hline Statistic & CF & EEDS & SZWQ & HLBE & Total \\
\hline Tested & 219 & 85 & 30 & 74 & 408 \\
\hline Infected & 106 & 23 & 15 & 63 & 207 \\
\hline Infection rate & 48.40 & 27.06 & 50 & 85.14 & 50.74 \\
\hline
\end{tabular}

Table 4 Haplotype distribution of Rickettsia based on gltA gene

\begin{tabular}{|llllll|}
\hline Hap & Num & CF & EEDS & HLBE & SZWQ \\
G1 & 167 & 77 & 20 & 60 & 10 \\
G2 & 25 & 20 & 1 & 2 & 2 \\
G3 & 7 & 6 & 0 & 0 & 1 \\
G4 & 1 & 1 & 0 & 0 & 0 \\
G5 & 1 & 1 & 0 & 0 & 0 \\
G6 & 1 & 1 & 0 & 0 & 0 \\
G7 & 1 & 0 & 0 & 0 & 1 \\
G8 & 1 & 0 & 0 & 0 & 1 \\
G9 & 1 & 0 & 1 & 0 & 0 \\
G10 & 2 & 0 & 1 & 1 & 0 \\
\hline
\end{tabular}


Table 5 Summary statistics for polymorphisms and neutrality tests of gltA gene from Rickettsia in Inner Mongolia

\begin{tabular}{|llllllll|}
\hline & $\mathrm{n}$ & $\mathrm{Ht}$ & $\mathrm{S}$ & $\mathrm{Hd}$ & $\mathrm{Pi}$ & Tajima's & Fu's Fs \\
\hline CF & 106 & 14 & 400 & 0.484 & 0.06725 & -1.47773 & 47.607 \\
\hline EEDS & 23 & 12 & 445 & 0.909 & 0.04918 & -2.72424 ** & 8.007 \\
\hline HLBE & 63 & 6 & 10 & 0.313 & 0.00064 & $-2.13550^{\star}$ & -2.666 \\
\hline SZWQ & 15 & 9 & 308 & 0.800 & 0.13230 & -1.12826 & 9.686 \\
\hline TOTAL & 207 & 10 & 282 & 0.335 & 0.04922 & -1.65779 & 46.426 \\
\hline
\end{tabular}

Abbreviation: $\mathrm{n}$, number of samples; $\mathrm{Ht}$, number of haplotypes; $\mathrm{S}$, number of polymorphic sites; $\mathrm{Hd}$, haplotype diversity; $\mathrm{Pi}$, nucleotide diversity. ${ }^{*} p<0.05 ;{ }^{* \star} p<0.01 ;{ }^{* \star \star} p<0.001$

Table $6 \mathrm{~F}_{\mathrm{ST}}$ values among different groups of Rickettsia based on gltA gene

\begin{tabular}{|lllll|}
\hline Locality & CF & EEDS & HLBE & SZWQ \\
\hline CF & & & & \\
EEDS & -0.02141 & & & \\
HLBE & 0.04136 & 0.04878 & & \\
SZWQ & -0.00537 & -0.00118 & 0.25240 & \\
\hline
\end{tabular}

Table 7 AMOVA of gltA gene of Rickettsia population

\begin{tabular}{|lcclll|}
\hline $\begin{array}{l}\text { Source of } \\
\text { variation }\end{array}$ & d.f & $\begin{array}{l}\text { Sum of } \\
\text { squares }\end{array}$ & $\begin{array}{l}\text { Variance } \\
\text { Components }\end{array}$ & $\begin{array}{l}\text { Percentage of } \\
\text { variation }\end{array}$ & $\begin{array}{c}\text { Fixation } \\
\text { Idex } \\
\text { FST }\end{array}$ \\
$\begin{array}{l}\text { Among } \\
\text { population } \\
\begin{array}{l}\text { Within } \\
\text { population }\end{array}\end{array}$ & 3 & 75.094 & $0.30572 \mathrm{Va}$ & 2.52684 & \\
$\begin{array}{l}\text { Total } \\
\text { Total }\end{array}$ & 203 & 294.027 & $11.79324 \mathrm{Vb}$ & 97.47316 & 0.02527 \\
& 206 & 2469.121 & 12.09896 & & \\
\hline
\end{tabular}


Table 8 Haplotype distribution of Rickettsia based on ompA gene

\begin{tabular}{|llllll|}
\hline Hap & Num & CF & EEDS & HLBE & SZWQ \\
01 & 59 & 33 & 8 & 10 & 8 \\
02 & 85 & 35 & 13 & 34 & 3 \\
03 & 26 & 21 & 1 & 2 & 2 \\
04 & 3 & 3 & 0 & 0 & 0 \\
05 & 2 & 2 & 0 & 0 & 0 \\
06 & 2 & 2 & 0 & 0 & 0 \\
07 & 1 & 1 & 0 & 0 & 0 \\
08 & 1 & 1 & 0 & 0 & 0 \\
09 & 1 & 1 & 0 & 0 & 0 \\
010 & 3 & 3 & 0 & 0 & 0 \\
011 & 1 & 1 & 0 & 0 & 0 \\
012 & 1 & 1 & 0 & 0 & 0 \\
013 & 1 & 1 & 0 & 0 & 0 \\
014 & 1 & 1 & 0 & 0 & 0 \\
015 & 1 & 0 & 0 & 0 & 1 \\
016 & 1 & 0 & 1 & 0 & 1 \\
017 & 8 & 0 & 0 & 8 & 0 \\
018 & 5 & 0 & 0 & 5 & 0 \\
019 & 1 & 0 & 0 & 1 & 0 \\
020 & 1 & 0 & 0 & 1 & 0 \\
021 & 1 & 0 & 0 & 1 & 0 \\
022 & 1 & 0 & 0 & 1 & 0 \\
\hline 0
\end{tabular}

Table 9 Summary statistics for polymorphisms and neutrality tests of ompA gene from Rickettsia in Inner Mongolia 


\begin{tabular}{|llllllll|}
\hline & $\mathrm{n}$ & $\mathrm{Ht}$ & $\mathrm{S}$ & $\mathrm{Hd}$ & $\mathrm{Pi}$ & Tajima's & Fu's Fs \\
\hline CF & 106 & 15 & 11 & 0.765 & 0.00394 & -0.26745 & -3.216 \\
\hline EEDS & 23 & 12 & 43 & 0.889 & 0.00947 & $-2.21147 \star \star$ & -1.104 \\
\hline HLBE & 63 & 15 & 365 & 0.739 & 0.19544 & 1.53899 & 58.425 \\
\hline SZWQ & 15 & 15 & 57 & 1 & 0.02468 & -1.48940 & -5.059 \\
\hline TOTAL & 207 & 22 & 349 & 0.735 & 0.07308 & -1.08797 & 48.645 \\
\hline
\end{tabular}

Abbreviation: $\mathrm{n}$, number of samples; $\mathrm{Ht}$, number of haplotypes; $\mathrm{S}$, number of polymorphic sites; $\mathrm{Hd}$, haplotype diversity; $\mathrm{Pi}$, nucleotide diversity. * $p<0.05$; $* \star p<0.01$; $* \star \star ~ p<0.001$

Table $10 \mathrm{~F}_{\mathrm{ST}}$ values among different groups of Rickettsia based on ompA gene

\begin{tabular}{|lllll|}
\hline Locality & CF & EEDS & HLBE & SZWQ \\
CF & & & & \\
EEDS & 0.04464 & & & \\
HLBE & 0.25852 & 0.13410 & & \\
SZWQ & 0.01902 & 0.01996 & 0.11367 & \\
\hline
\end{tabular}

Table 11 AMOVA of ompA gene of Rickettsia population

\begin{tabular}{|lcclll|}
\hline $\begin{array}{l}\text { Source of } \\
\text { variation }\end{array}$ & d.f & $\begin{array}{l}\text { Sum of } \\
\text { squares }\end{array}$ & $\begin{array}{l}\text { Variance } \\
\text { Components }\end{array}$ & $\begin{array}{l}\text { Percentage of } \\
\text { variation }\end{array}$ & $\begin{array}{c}\text { Fixation } \\
\text { Idex } \\
\text { FST }\end{array}$ \\
\hline $\begin{array}{l}\text { Among } \\
\text { population } \\
\begin{array}{l}\text { Within } \\
\text { population }\end{array}\end{array}$ & 3 & 691.719 & $4.90433 \mathrm{Va}$ & 21.21763 & \\
$\begin{array}{l}\text { Total } \\
\text { Total }\end{array}$ & 203 & 3696.644 & $18.21007 \mathrm{Vb}$ & 78.78237 & 0.21218 \\
& 206 & 4388.362 & 23.11439 & & \\
\hline
\end{tabular}

\section{Figures}




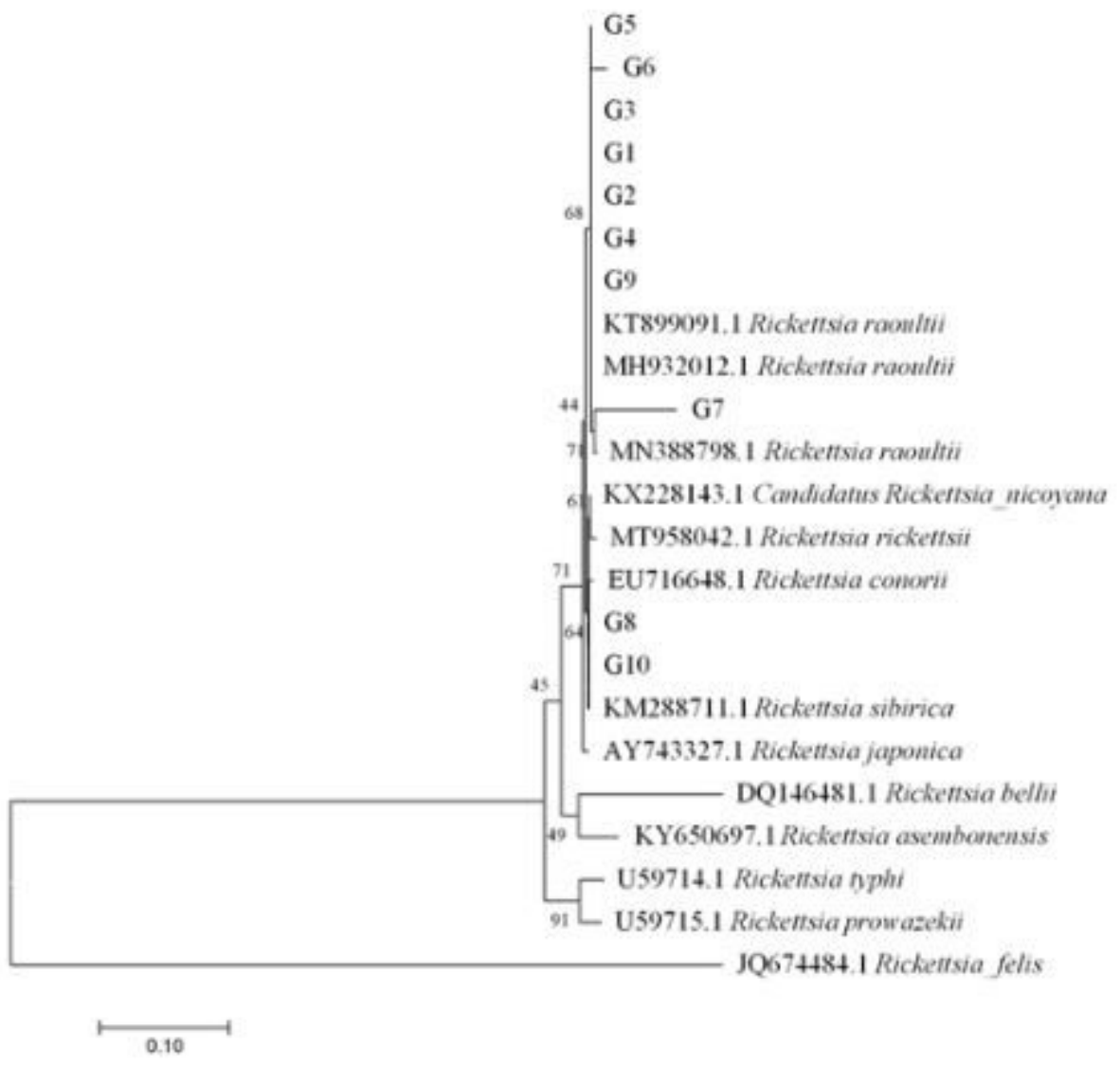

\section{Figure 1}

Phylogenetic tree based on gltA gene of Rickettsia raoultii 


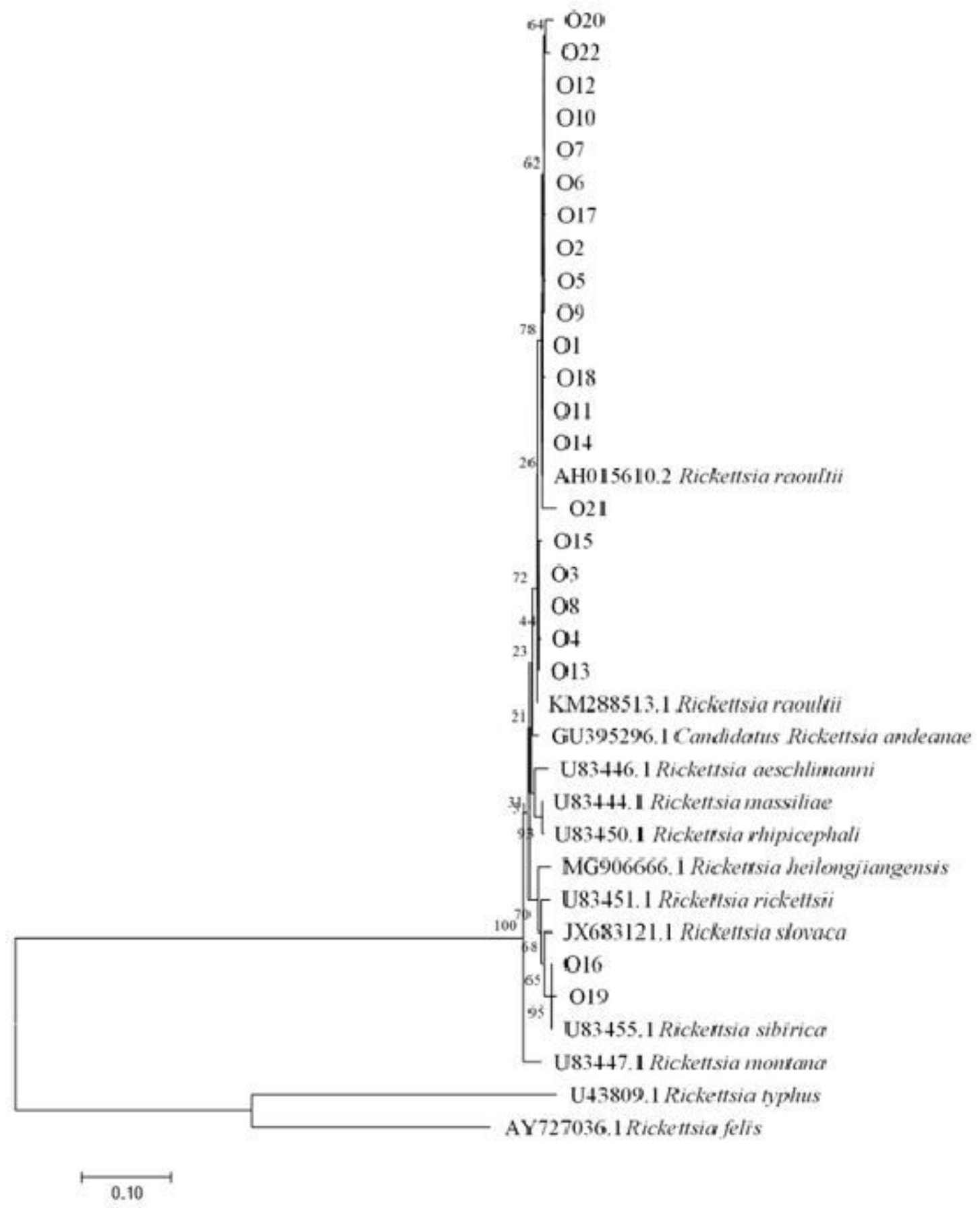

Figure 2

Phylogenetic tree based on ompA gene of Rickettsia raoultii 
a

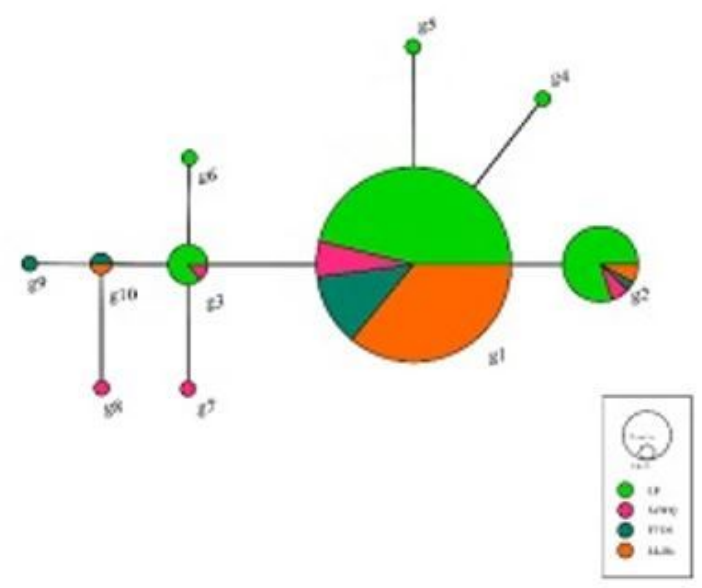

b

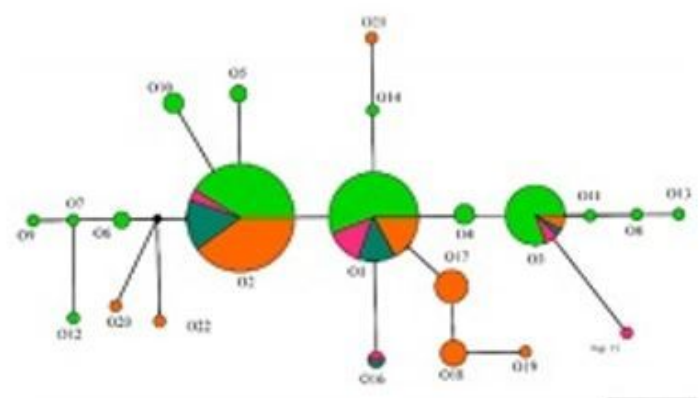

:

\section{Figure 3}

a TCS haplotypes network of Rickettsia raoultii based on gltA gene from four different populations in Inner Mongolia b TCS haplotypes network of Rickettsia raoultii based on ompA gene from four different populations in Inner Mongolia

a

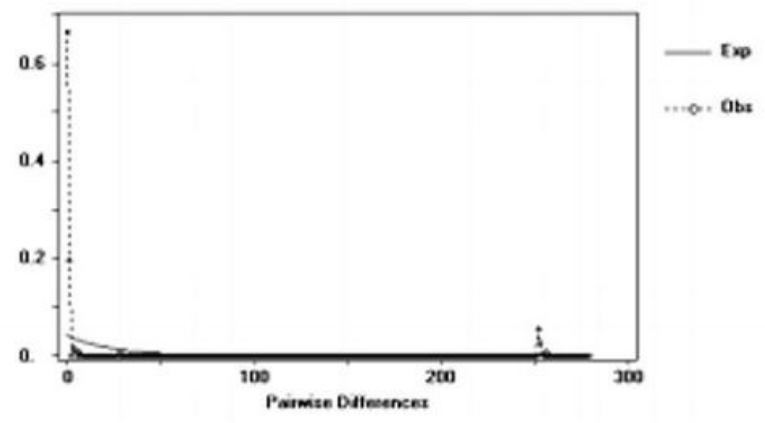

b

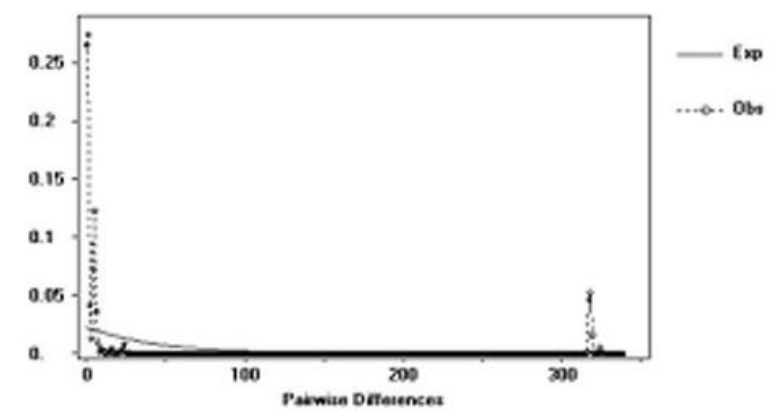

\section{Figure 4}

a Mismatch distribution analysis for the Rickettsia raoultii groups based on gltA b Mismatch distribution analysis for the Rickettsia raoultii groups based on ompA 


\section{Supplementary Files}

This is a list of supplementary files associated with this preprint. Click to download.

- GraphicalAbstract.tif 